\title{
Herencia y cuidado: transiciones en la obligación filial
}

\author{
Leticia Robles Silva \\ y María Daniela Rosas García
}

\begin{abstract}
El objetivo del presente texto es analizar el discurso moral sobre la obligación filial y su sistema de recompensa para comprender el papel de la herencia en el cuidado. Los datos provienen de dos trabajos de campo, uno con ancianos y otro con jóvenes de los sectores populares de Guadalajara, México. La obligación filial continúa siendo un ciclo de reciprocidad de cuidado entre padres e hijos, mientras que su sistema de recompensa experimenta un proceso de transición cuando la herencia deja de ser una forma de recompensa y es sustituida por otras expresiones de gratitud basadas en el capital social.
\end{abstract}

PALABRAS CLAVE: obligación filial, cuidado, herencia, recompensa, discurso moral

\section{Inheritance and Caring: Transitions in Filial Obligation}

The aim of this paper is to analyze the moral discourse on the filial obligation norms and the expression of gratitude to explain the role of inheritance in old parents caring. Data derives from two fieldworks carried out, one with young and the other with elderly people, from a popular sector in Guadalajara, Mexico. The filial obligation norms continue unchanged as part of a caring reciprocity cycle between parents and children, nevertheless, a transition occurs in the reward system when inheritance is replaced as a reward by other expressions of gratitude based on social capital.

KEYWORDS: filial obligation, caring, inheritance, gratitude, moral discourse

Leticia Robles Silva: Universidad de Guadalajara, Guadalajara, Jalisco, México leticia.robles.silva@gmail.com

María Daniela Rosas García: Universidad de Guadalajara, Guadalajara, Jalisco, México mariadaniela.rosas@gmail.com 


\section{INTRODUCCIÓN}

$\mathrm{H}$ eredar a quien nos cuida era una costumbre. Para quien cuidó a una persona recibir una herencia era una recompensa. Sin embargo, al igual que otros cambios registrados en las familias en las últimas décadas, la costumbre se desvanece a inicios del siglo XXI y ahora no siempre se hereda a quien cuidó por el bienestar de alguien. El papel de la herencia en el cuidado data de varios siglos atrás. En la literatura está reportado que de los siglos XVI al XIX, aunque la ley establecía la distribución de la herencia en partes iguales entre los hijos, la costumbre era heredar a un hijo a cambio de cuidado (Hareven, 1994: 8). En España, Portugal, Inglaterra y la zona mediterránea europea los padres utilizaban la mejora - una tercera o quinta parte de la herencia - para favorecer al hijo o la hija que los cuidó (Green y Owens, 2004: 17; BenAmos, 2000: 301-302; Kertzer y Brettell, 1987: 9697) o el contrato de retiro para designar como única cuidado (Poska, 2000: 319-320).

Lejos de ser una estrategia ajena a las familias latinoamericanas, esta práctica se reprodujo entre las elites novohispanas de los siglos XVII al XIX como parte de las costumbres transferidas de los imperios europeos a sus colonias. En México está documentado el uso de la mejora para recompensar a la hija o nieta que cuidó de los padres o los abuelos (Lamar, 1994: 128; Couturier, 1985: 296). Entre las elites indígenas, el esposo heredaba las tierras a los hijos y hermanos para que cuidaran a su esposa, y las esposas heredaban a hijas y nietas que las cuidaron (Kellogg, 1986: 318-320). Esta costumbre se perpetúa como la norma de la ultimagenitura en la primera mitad del siglo xx. Entre los campesinos e indígenas mesoamericanos, la casa se heredaba al hijo ultimogénito, quien cuidaba a los padres ancianos (Robichaux, 1997: 160-161). En zonas rurales del centro de México, las mujeres viudas o solas heredaban la casa a una hija a cambio de cuidado (Levine, 1986: 235). En las sociedades rancheras del

occidente, la hija ultimogénita permanecía soltera para cuidar a sus padres y a cambio heredaba la casa y parte de las propiedades (Arias, 2005: 554-556).

En el transcurso de la segunda mitad del siglo $\mathrm{xx}$ y principios del siglo XXI no siempre se hereda a quien cuidó a sus padres. A pesar de que mujeres pobres en Guadalajara conocían esta costumbre, no hacían testamento y preferían sólo manifestar su deseo de dejar la casa al hijo que vivía con ellas (Ward et al., 2011: 475; Varley y Blasco, 2000: 52). Los varones ejidatarios en zonas rurales de Veracruz ya no heredan a un hijo sino a su esposa con el fin de que los hijos la cuiden por el interés del ejido o para que ella trabaje la tierra si es abandonada (Del Rey, 2005: 176-177). En sectores populares urbanos tampoco heredan las hijas que cuidaron a sus padres, pues el beneficiario es algún otro hermano (Robles, 2007: 360; Arias, 2004: 31-33), y en áreas rurales del occidente la herencia de tierras agrícolas perdió valor como mecanismo de recompensa del cuidado frente a la vida urbana (Arias, 2009: 225).

En este recuento histórico se muestra que la herencia es parte de las prácticas de los padres cuando reciben cuidado de sus hijos, pero esta costumbre ha perdido fuerza entre algunos grupos sociales en las últimas décadas. Sin embargo, no sabemos si también se registran cambios de tipo normativo respecto de si las reglas para recompensar se han modificado. De ahí nuestro interés en esta dimensión normativa en torno al cuidado de los padres y la recompensa al hijo o hija que los cuidó. La obligación filial es la expresión moral y normativa del cuidado a los padres ancianos. Es una obligación por reciprocidad que los hijos adquieren por el apoyo, el cuidado o la crianza recibida de los padres durante la infancia. David Robichaux (1997 y 2007) y Patricia Arias (2004, 2005 y 2009) describen el funcionamiento de la norma de la ultimagenitura en México. Ambos autores destacan otro ciclo de reciprocidad, la recompensa que los padres otorgan al hijo o la hija quien los cuidó, que es la herencia. Para entender el ciclo de reciprocidad retomamos la propuesta de Mauss (2009: 71, 155-177) de un 
ciclo de dar-recibir-devolver y es indispensable comprender la regla que obliga a dar y a devolver. Es decir, identificar las reglas que obligan a cuidar a los padres y las que obligan a recompensar al hijo o a la hija que los cuidó.

De acuerdo con Kittay (1999: 31), el cuidado por condiciones de dependencia es una obligación moral basada en la reciprocidad. Una vía para analizar la dimensión moral es la moralidad del sentido común, entendida como los pensamientos, creencias e intuiciones que posee cualquier individuo para deliberar moralmente sobre las acciones e interacciones que deben realizarse o son deseables en la vida cotidiana y de cómo actuar en las interacciones cotidianas (Beauchamp, 2003: 260-263). Para identificar cambios en las reglas de reciprocidad en torno al cuidado y la recompensa optamos por un análisis comparativo entre generaciones, estrategia metodológica aplicada a los cambios sociales. Esto implica comparar una "vieja generación" versus una "joven generación” respecto de eventos, prácticas, interpretaciones o condiciones sociales, con el propósito de identificar cambios y continuidades en la vida social (McLeod y Thomson, 2009: 108 y 112). También retomamos la definición de Mannheim (1963: 382) de que una generación es una identidad de localización referente a un grupo de edad, el cual comparte las mismas experiencias e interpretaciones de la vida social en un contexto social e histórico particular, de manera que los cambios y continuidades registrados entre una y otra generación dan razón de los procesos de transformación de una sociedad. Por último, nuestro interés es indagar si hay ajustes en la dimensión normativa de la obligación filial en sectores populares urbanos, uno de los grupos en los cuales se reporta un debilitamiento en la práctica de heredar al hijo o la hija que cuidó de sus padres. Nuestro objetivo es examinar si han ocurrido cambios en la dimensión normativa de la obligación filial y la recompensa en sectores populares urbanos a través de un análisis de la moralidad del sentido común desde la perspectiva de dos generaciones.

\section{METODOLOGÍA}

El material de campo proviene de dos estudios, uno con ancianos y el otro con jóvenes que residían en los barrios de Oblatos y Santa Cecilia en Guadalajara. ${ }^{1}$ Los ancianos pertenecen a la cohorte generacional de 1908-1940 y los jóvenes a la de 1974-1986, y ambos grupos fueron entrevistados a inicios del siglo xxi. Esto cumple con el criterio de compartir la misma circunstancia histórica y social para registrar cambios sociales y una diferencia de 30 años de edad entre una y otra generación para fines analíticos (Mannheim, 1963: 389). Ambas generaciones comparten la misma época y la misma localización en un contexto de envejecimiento poblacional caracterizado por convivencias más prolongadas entre abuelos y nietos, y de una creciente demanda de cuidado a los ancianos satisfecha casi siempre por la familia. Los ancianos y los jóvenes no tienen relación de parentesco entre sí ni pertenecen a la misma familia, ya que no nos interesan los cambios en las relaciones intrafamiliares sino en

Las entrevistas a los ancianos son parte de un estudio multicéntrico, aquí sólo se utiliza el material de campo de Guadalajara obtenido en 2002. Una conocida permitió a la primera autora el contacto con ancianos de un grupo de convivencia, quienes a su vez refirieron a otros ancianos. En el estudio participaron 17 ancianos, diez mujeres y siete hombres, ${ }^{2}$ con 74 años de edad en promedio.

\footnotetext{
${ }^{1}$ Tanto Oblatos como Santa Cecilia son barrios de los sectores populares desde la década de 1980, cuando se consolidaron dichos asentamientos urbanos (Vázquez, 1992: 50). Estos barrios se localizan en la zona noreste de la metrópoli de Guadalajara y son clasificados como clústeres de pobreza urbana (SánchezPeña, 2012: 170). Según Oxhorn (1998: 231-232), los sectores populares incluyen a los trabajadores con un empleo más o menos estable en la economía formal y grandes contingentes de trabajadores en el sector informal, sin prestaciones laborales ni representación sindical, cuyos ingresos les permiten resolver sólo una parte de sus necesidades

2 Durante la selección se intentó reunir un número similar de hombres y mujeres para la comparación por género. Sin embargo,
} 
Ocho de los ancianos eran casados, seis viudos y tres solteros. Los ancianos con hijos tenían cuatro hijos vivos en promedio. Tres ancianos y una anciana no tuvieron hijos. La mayoría eran analfabetas o sólo sabían leer y escribir. Siete de las ancianas y todos los hombres fueron trabajadores remunerados, sólo ocho percibían una pensión y 11 eran propietarios de sus casas. Los dueños de las viviendas de aquellos que declararon no ser propietarios de las mismas eran las esposas, la madre y un ahijado. Sólo dos hombres ancianos rentaban su vivienda. Diez ancianos vivían en hogares de familias extensas de dos o tres generaciones, tres vivían sólo con su pareja, otros tres vivían solos y una anciana vivía con dos hijas solteras. Todos padecían alguna enfermedad crónica, 13 eran dependientes en algún grado y eran cuidados por una hija o una hermana.

El estudio con los jóvenes replica el llevado a cabo con los ancianos. Los jóvenes fueron contactados por medio de una "bola de nieve" a partir de los sujetos conocidos de una de las entrevistadoras, quien el cuidador secundario. Además, cuatro jóvenes mujeres apoyaban a sus madres en el cuidado de sus abuelos, quienes residían en casa separada.

La guía de entrevista contenía dos temas: el primero era sobre sus expectativas del cuidador ideal, el segundo indagaba sobre sus creencias referentes al deber ser de la obligación y la recompensa. Las preguntas fueron del tipo: ¿por qué se debe cuidar a los padres ancianos?, ¿qué recibe a cambio quien cuidó?, ¿qué debería recibir a cambio quien cuidó? A los ancianos se les entrevistó en dos ocasiones y cada entrevista tuvo una duración de dos horas en promedio. Los jóvenes fueron entrevistados en una sola sesión, cuya duración fue de entre una y dos horas. Las grabaciones de las entrevistas fueron transcritas verbatim y después se exportaron al programa The Ethnograph 6.0.

La moralidad del sentido común, al ser parte de la vida subjetiva de los individuos, sólo es accesible a través del discurso (Bergmann, 1998: 282-285), por eso realizamos un análisis del discurso según la propuesta de Norman Fairclough. En la primera fase se hizo una lectura línea por línea del corpus total de cada entrevista para identificar los segmentos que aludieran a las razones para cuidar a los padres ancianos y a la recompensa. Una vez codificados los segmentos, se analizaron los juicios del hablante respecto de la obligación en dos aspectos: en la modalidad del grado de compromiso del hablante en relación con la verdad y la necesidad, y la evaluación discursiva del grado de compromiso del hablante en función de lo deseable o indeseable y lo bueno o lo malo (Fairclough, 2003: 164-190).

En la primera etapa se hizo un análisis sintáctico para identificar la modalidad de obligación o evaluativa contenida en los enunciados. Este análisis clasificó el texto de la entrevista por su estructura oracional en: a) tipo de oraciones simples según actitud del hablante, ya fueran enunciativas, imperativas o exhortativas y desiderativas, y según la estructura en personales o impersonales; b) oraciones complejas causales y condicionales; c) perífrasis verbales de obligación y necesidad; d) tiempos verbales;

la feminización de la vejez y los crecientes niveles de dependencia entre los mayores de 75 años impidieron tener una muestra equiparable por sexo. 


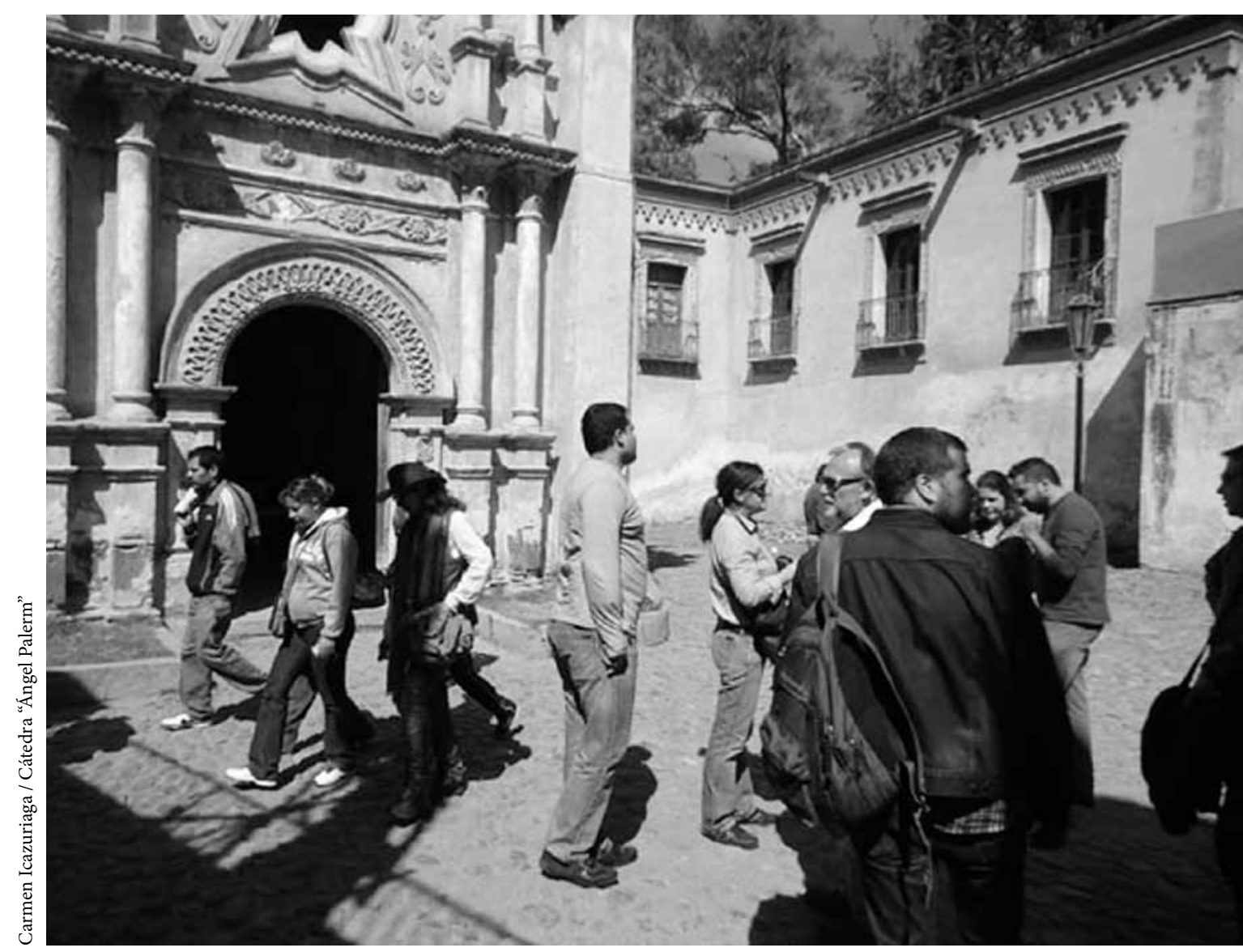

En el interior de la exhacienda de Molino de Flores. Serie: Lectura del paisaje: Sistemas de riego en el Acolhuacan septentrional, 2014.

e) sujetos gramaticales; f) léxico para referirse a cuidado y recompensa, y g) marcadores discursivos subjetivos de modalidad asertiva como "yo digo".

Posteriormente, analizamos los mismos segmentos sobre la acción discursiva argumentativa a partir del texto de Deanna Kuhn (1991), quien documenta la forma de argumentación del hombre común en la vida cotidiana. Se identificaron las razones para cuidar a los padres ancianos y la forma de recompensar a quien cuidó, con sus correspondientes argumentos y contraargumentos, refutaciones $y$ evidencias, y construimos categorías de razones para cuidar y para recompensar. En la última etapa trabajamos de manera simultánea con los productos de las dos fases previas para determinar el contenido de la proposición moral enunciada, sus condiciones de aplicabilidad, la especificidad del contenido y el tono de obligatoriedad utilizado (Baier, 1966: 210-211). La aseveración y su argumentación fueron tipificadas en proposiciones de obligación, de hecho, de deseabilidad y de posibilidad con base en la identificación en cada argumentación tanto de su contenido como de su forma de enunciación en la estructura oracional. Por ejemplo, la proposición de obligación se definía por ser argumentada como una obligación y ser dicha con oraciones en tiempo verbal imperativo o de perífrasis con infinitivo mediato o el uso de verbos modales de obligación como "deber" o "tener que". Además identificamos la posición del hablante a partir del sujeto gramatical 
para referirse a sí mismo, el uso de narraciones de experiencias personales para ejemplificar sus argumentaciones y de marcadores discursivos de modalidad subjetiva. Se contrastaron las aseveraciones y las argumentaciones entre hombres y mujeres al interior de cada generación, pero no se establecieron diferencias por sexo. Finalmente se compararon las argumentaciones de los ancianos versus las de los jóvenes.

\section{DOS CICLOS DE RECIPROCIDAD: CUIDAR Y RECOMPENSAR}

En un ciclo de reciprocidad alguien inicia dando y quien recibió devuelve. En ambas generaciones la obligación filial y la recompensa son ciclos de reciprocidad independientes y cada uno funciona con reglas propias. La obligación filial es una obligación y la recompensa es una deuda de gratitud.

\section{La obligación filial: recibir y devolver cuidado}

La obligación de los hijos de cuidar a sus padres se genera bajo dos circunstancias: por lo recibido en el pasado o por el vínculo de parentesco. La obligación por lo recibido en el pasado es la más importante, 11 de los 17 ancianos y 22 de los 32 jóvenes la refirieron, y fue la más desarrollada argumentativamente y apoyada con evidencias. Éste es un ciclo de reciprocidad paralela diferida en tiempo. Si los padres cuidaron de los hijos durante su infancia, entonces tienen el derecho a recibir cuidado de sus hijos durante su vejez. Así, el intercambio es un mismo servicio, los padres dan el cuidado durante la niñez y los hijos lo devuelven en la vejez. La diferencia entre ambas generaciones es cómo se genera y cuándo es una demanda justificada.

Para los ancianos la obligación de los hijos de cuidar a sus padres es una regla universal e incuestionable y lo expresan con el refrán "se cosecha lo que se sembró", cuyo significado es: quien vive bien, cosechará bienestar; quien vive mal, cosechará el mal. Las palabras de doña Dolores - "un granito que sembramos y lo cultivamos, ya de allí, cómo los cuidamos, así nos cuidarán a nosotros"sintetizan las condiciones de esta reciprocidad. La idea "cómo los cuidamos" tiene una doble acepción. Si cuidar es una obligación - era enunciada como tal—, "una es por la obligación que también tienen de cuidar", sembrar significa cuidar a los hijos durante su niñez y cosechar es recibir cuidado durante la vejez. El cuidado durante la niñez significa recibir un conjunto de beneficios como instruir, educar y dirigir. La descripción de don Rubén ilustra este argumento:

Pues en caso de la madre, porque ella les dio el ser, porque ella se preocupó por cuidarlos cuando eran bebés, cuando estaban muy chicos, porque les enseñó a ir a la iglesia o adorar a Dios en la forma que ellos tengan, según la religión a que pertenezcan, y porque tanto el padre como la madre, pues muchas veces se preocupan por llevar a los hijos a la escuela para que aprendan, para que en un futuro próximo sean personas útiles a la sociedad y se puedan mantener a sí mismos.

La segunda acepción del refrán es cuando no se tiene la obligación. Si los padres no cuidaron, maltrataron o abandonaron a sus hijos durante la infancia, entonces no es lícito por parte de los padres esperar ser cuidados por los hijos durante la vejez. Para ejemplificar este argumento se expusieron historias de ancianos conocidos, vecinos, amigos o parientes, a quienes sus hijos no cuidaron o lo hicieron de manera limitada. Don Juan narraba la historia de su hermana, que a sus 80 años está casi abandonada por su hija:

el tratamiento [el cuidado] que le dio a la hija no fue muy bueno, entonces la hija no encontró cariño en ella y pues se cansó de ella. Y estaba mala, entonces, no hace tanto se puso enferma y la hija la llevo ahí, a la Cruz Roja, y ya me avisaron. Me hablaron por 
teléfono y ya fui a ver, y sí, ahí estaba la hija, estaba con ella. Le hicieron análisis, se quedaron ese día. Así quedó y como a los ocho días de eso llegó [a mi casa] bien mala. Dice: "Margarita [su hija] me dijo que viniera contigo, me dijo que tú me ibas a dar las medicinas". Ya le dije: "Bueno, aquí quédate unos días para ver qué hacemos".

Éste fue uno de los varios episodios en los cuales la hija llevaba a su madre al hospital y ahí la dejaba. Don Juan justificaba su proceder porque su hermana no cuidó de su hija cuando era niña. Historias similares se repitieron durante las entrevistas. El eje narrativo era un padre o una madre que no se responsabilizaron de cuidar a sus hijos de manera adecuada y ahora durante su vejez estaban abandonados, se les atendía esporádicamente o incluso eran maltratados. De ahí la conclusión de doña Dolores: "eso sembró, eso cosechó".

En cambio, para los jóvenes la obligación permanece aun cuando los padres no cuidaron a sus hijos en el pasado, como afirmaba Ricardo: "como hayan cuidado, porque uno se debe de fijar, no en lo que hayan dado, sino en lo que tenemos que hacer más bien". La noción de obligación era tener una deuda moral con los padres tanto por el sacrificio y los esfuerzos hechos como por los recursos proporcionados en el pasado. Por eso los hijos están obligados a dar cuidado y atención a sus padres ancianos. Esta noción de deuda fue expresada en estos términos: "yo en algún momento tengo también que, pues, retribuirles, recompensarles por lo que ellos me han dado" o "a quien le debes muchísimas cosas". Otra diferencia fue que los jóvenes se expresaban en primera persona al hablar de su propia condición como hijos y la obligación hacia sus padres, en tanto que el discurso de los ancianos era en tercera persona en sus variantes impersonales y aludía a la obligación universal de los hijos, pero no a la suya ni a la de sus hijos.

Para los ancianos el cuidado estaba orientado a formar individuos independientes y autónomos. Los jóvenes referían dos tipos de cuidado: uno que sólo proporciona recursos materiales y sociales, percibidos como beneficios y apoyo, que generan una obligación, y otro que además de lo anterior está revestido de afecto, de modo que entonces la reciprocidad no se basa en la obligación sino en una acción voluntaria originada en el afecto. Esta última acepción alude al rasgo enfatizado por la corriente feminista de que el cuidado es simultáneamente trabajo y amor (Kittay, 1999: 25). En el discurso de Lucía cuidar es una obligación, pero cuando es una acción voluntaria - "que te nazca querer cuidarlo" - se trata de una acción motivada por el cariño hacia la persona. Como evidencia, narraba la historia de su abuelo y su tío. Primero describe a su abuelo como "una persona muy recia", cuya actitud con sus hijos "nunca fue buena":

no fue un hombre cariñoso, no fue un hombre compasivo, no fue una persona tolerante, o sea, más bien fue una persona autoritaria, mandón, grosero con los hijos, entonces más que ganas de cuidarlo, ellos sentían una obligación.

El tío era lo opuesto: amoroso, compasivo, tierno:

con mi tío Carlos es diferente, a él lo cuidas porque él es un hombre que te inspira ternura, que dices "pobrecito". En ocasiones hasta compasión por su misma enfermedad, entonces yo creo que eso también puede llevarte a querer cuidar a una persona, la actitud que haya tenido en su vida para con tu persona.

La historia no niega que el abuelo haya cuidado de sus hijos, subraya que dicho cuidado estuvo desprovisto de amor y que bajo esa circunstancia el cuidado a los padres es una obligación, pero cuando el cuidado y la relación padre-hijo estuvo revestida de amor la reciprocidad es un acto voluntario cuya motivación se fundamenta en el afecto construido en el vínculo intergeneracional. Una regla secundaria de la obligación filial fue el vínculo de parentesco. Ambas generaciones expresaron sólo una sentencia breve y certera: se cuida "porque son sus padres", sin 
argumentos ni evidencias. El simple parentesco padre-hijo genera obligación de cuidado, sin importar beneficios recibidos ni intercambios pasados o presentes. A diferencia de la regla anterior, en ésta ni se mitiga ni desaparece la obligación. No importa cómo desempeñaron los padres su rol, si cumplieron su deber de padres o la calidad del cuidado, la obligación persiste. Doña Margarita argumentaba:

de todos modos si ya le toca a uno la mala suerte que sean así sus papás, que no hagan caso de sus hijos, pues de todos modos sus hijos tienen que verlos [cuidarlos], yo digo, uno no va a pagar lo que sus padres de uno hagan, ellos van a pagar lo que hicieron con uno, porque son sus padres de todos modos, y les dieron la vida, tienen que verlos porque son sus padres.

La única diferencia fue que los jóvenes extendieron la obligación a los abuelos porque eran los padres de sus padres. Esta alusión a una obligación extendida refleja en cierta medida el actual contexto social de envejecimiento, en el que la convivencia de abuelos y nietos es más frecuente y también es mayor la presencia de experiencias de cuidado en las familias. Recordemos que algunos de los jóvenes participaban en el cuidado de sus abuelos. Por otra parte, la herencia apareció como un motivo para el cuidado a los padres en el discurso de sólo tres ancianos. Ésta podía ser un motivo para que los hijos o incluso los nietos cuidaran de los padres o de los abuelos porque esperaban recibir a cambio la casa, dinero o algún bien. Doña Rafaela explicaba que en muchas ocasiones el cuidado se da por interés: "Habemos muchas [personas] que por interés que le den alguna cosa, por eso lo hacemos a veces. Porque si usted ve que el anciano tiene dinero, tiene algo, 'a ver si me toca algo a mím.' En esta circunstancia el cuidado no era parte de un ciclo de reciprocidad, sino un intercambio de cuidado por herencia. En síntesis, la obligación filial es un ciclo de reciprocidad cuya obligación se genera por el cuidado otorgado durante la niñez, que es devuelto durante la vejez.

\section{La recompensa: una deuda de gratitud}

Ambas generaciones reconocen la necesidad de recompensar a quien cuidó. Éste es un ciclo de reciprocidad oblicua diferida o no en el tiempo, cuya obligación se sustenta como una "deuda de gratitud". Una característica en los discursos de ancianos y jóvenes fue el predominio del habla impersonal y la alusión a los padres con el léxico de anciano o persona, es decir, daban mayor importancia al dilema moral de la recompensa que a los sujetos implicados en este ciclo. Trece de los ancianos admitían implícita o explícitamente que debía gratificarse a quien cuidó, como don Juan: "Pues de merecer, pues yo digo que sí". La deuda de gratitud se origina por el beneficio recibido con el cuidado, pero sobre todo por reconocer el sacrificio y el esfuerzo adicional realizado durante el cuidado. Para doña Margarita la recompensa era justa:

\footnotetext{
Margarita: Pos tienen que darle a la persona que los lía, ¿verdad? Yo digo, pues quién sabe. Porque pos tienen derecho a que, si aquella persona lidió a aquel ancianito y si él tiene modo, pues sí, su lana [dinero] le tiene que dar, cuando están conscientes ellos, ¿verdad?

Entrevistador: ¿Sí merecen?

Margarita: ¡Cómo no, es mucho trabajo! Porque lidiar a un ancianito es mucho trabajo. Le suda [uno] mucho para hacer las cosas: desveladas, noches sin dormir, y lidiarlos pues es mucho trabajo.
}

La forma de recompensar era diferente si los ancianos entrevistados eran o no propietarios de su casa. Para nueve de los 11 ancianos dueños de su casa la herencia es la recompensa idónea, mientras que quienes no eran propietarios remitían a la recompensa no material. Si un anciano era propietario, había certeza de la herencia para quien cuidó, como dijo doña Esther: "si tiene bienes, de seguro se los van a dejar". Como prueba narraban historias de conocidos. Doña Maura relataba la historia de una pareja de ancianos que fueron cuidados por uno de sus hijos y su nuera: 
Aquí están unos señores, ya se murieron los señores, las hijas no los vieron, la nuera dizque no las dejaba entrar, dizque. Se murieron y dejaron al hijo [quien los cuidó] dueño de todo, y a los demás [nada les dejó], ni a las mujeres les dejó, y las hijas se pelearon.

En ocasiones quien cuidó no hereda. Esta afirmación se apoyaba en experiencias propias. Doña Margarita cuidó a su abuelo. A su muerte, sus tíos la excluyeron de la repartición de bienes durante el juicio de intestado: "cuando yo estuve joven, más joven, me tocó también cuidar a mi abuelito, pero a mí no me dieron nada". Situaciones similares fueron narradas por los ancianos respecto de sus esposas, quienes cuidaron a sus padres. En el caso de don José, que cuidó a su madre, los hermanos pelearon la herencia y la repartieron entre todos. La moraleja de estas historias es que si no hay un testamento como garantía, no hay herencia para quien cuidó. Por esta razón don José estaba en busca de un notario que no le cobrara mucho para hacer su testamento a favor del hijo que lo atendía porque sus otros 11 hijos no se preocupaban por él y no quería que la casa se repartiera entre todos: "porque ya me pasó una experiencia [narra lo del intestado de su madre], ya le digo, por eso no quiero pasar por lo mismo".

Si el anciano o la anciana fueran propietarios heredarían al cuidador. Cuando no, el anciano era incapaz de pagar su deuda de gratitud de acuerdo con lo esperado y quien cuidaba no recibía nada a cambio. Ésa fue la conclusión de doña Candelaria: "Si los padres tienen, les darán, y si no, pues ¿qué reciben? ¡Nada! Porque si no tiene uno nada, ¿qué pueden recibir de uno?". Seis ancianos no eran propietarios de las viviendas en las que residían y cuatro de ellos no definieron su posición ante este tema, optaron por no responder a pesar de reformular la pregunta de qué debe o debería recibir quien cuida. Su silencio hace pensar en la idea compartida por su generación: la gratitud se basa en la riqueza económica.

Los padres que no poseen bienes materiales para heredar plantean otras posibilidades para saldar su deuda. Dos ancianos no propietarios y una anciana propietaria recurrieron a dos alternativas de recompensa: la divina y el agradecimiento. La recompensa divina libera al anciano de la responsabilidad de recompensar y la asigna a un tercero: a Dios. Decía don Tomás: "Dios es el que le pagará esa obra que ha hecho". Y doña Esther señaló: "Aquí en la tierra no, ahí que se lo dejan a Dios [en el] cielo, pues ve su cheque llegando allá arriba". Como acabamos de anotar, la otra forma de recompensar es el agradecimiento. El anciano da la bendición o las gracias a su cuidador. Los ancianos exaltaban su valor moral. Don Gumersindo no poseía una casa para heredar, tal vez por esa razón no mencionó la herencia, pero si aludió a otras formas de gratitud en el sentido de que no todo se restringe a lo material sino que existen otros valores igual de relevantes:

entonces los mismos familiares reconocen la recompensa que deben de tener, no digamos una recompensa material, sino espiritual, unas personas que ni se conocían y estaban distanciadas en todo, ahí entran en comunión, la unión por medio de lo que hizo.

Esta valoración era suficiente como para no requerir una recompensa económica. De ahí que don Rubén asegurara: "No, pues eso es bastante, poder servir a alguien". Quien lo entrevistaba insistía en la posibilidad de alguna recompensa material y su respuesta fue un no rotundo seguido de la afirmación: "Para mí, eso es lo más importante”. Lo material era prescindible frente a este otro sistema de valores.

Los jóvenes expusieron un sistema de reglas distinto para recompensar. Una primera regla era rechazar la recompensa económica. Por cuidar "no se recibe nada a cambio" fue la respuesta de la mitad de los jóvenes, algunos la enunciaron en tono de obligación - "no debes recibir nada a cambio"-, otros en tono de certeza - "pues recibe a cambio nada”- y otros más como lo deseable — “yo pienso que a cambio no debería recibir nada"- - No estaban en contra de la recompensa, pero se oponían 
a recompensar económicamente a un familiar. Cuidar por el interés de una herencia o de una retribución económica era una conducta no aceptable desde la perspectiva de los jóvenes. Lorena describía a quienes actuaban así como personas movidas por el interés propio:

pero otros no se conforman, pero ya lo hacen, por decir, voy a cuidar a mi abuelito o a mi tío, lo que sea, pero para que me paguen, o sea, ya lo hacen con un interés. Si son [personas] interesadas, ahí están al pie, págame o dame eso, ya nomás están esperando a ver a qué horas les dan la recompensa.

Su desaprobación radicaba en el hecho de que esas personas buscaban el beneficio propio y no el bienestar del otro. Si alguien cuida por el interés de la herencia es como cobrarle al desamparado por la ayuda brindada. Jorge explicaba:

Un favor no se debe pagar, los favores no se pagan. Y no entiendo, si estoy cuidando a un anciano es porque yo voy a querer, no porque me están pagando, le estoy haciendo un favor, no porque acá yo quiera recibir algo, es lo que yo pienso.

La idea predominante es que ese tipo de personas ocultan su verdadera intención. Carlos comentaba: "Realmente eso es lo que busca la gente, ganar lo económico, pues no te lo dicen, eso no lo comentan, no te van a decir 'pues lo cuido porque me quiero quedar con la herencia. Eso no te lo dicen". Enunciados como "yo no lo haría por eso", "yo no le pediría nada a cambio", "no en mi punto de vista, pero bueno, se dan" eran introducidos para externar su rechazo y posición ante esa conducta. Es el caso de Vania:

Si tú lo haces con buena intención no hay necesidad de recibir nada a cambio. Pero, pues cuando lo haces con otras intenciones, pues a veces se ponen a pensar, bueno, no es mi forma de pensar, pero de algunas otras personas, de que por la herencia, que sí tienen dinero y todo eso.
La única circunstancia lícita de una retribución económica es cuando el cuidado se contrata como un trabajo y se paga por él un salario, sólo si quien lo desempeña no es un familiar. De modo que ellos distinguían dos tipos de cuidadores: los familiares que no deben recibir nada económico a cambio y aquellos contratados como cuidadores. Como decía Carlos: "personas que se dedican a cuidar gente", ya sea en instituciones o en las casas. Para Lorena dicho salario es inferior al trabajo que realizan, "entonces, muchas veces no remuneran muy bien, creo es un trabajo que debe ser bien pagado porque están ayudando a una parte importante de la sociedad". Ellos reconocían la existencia del cuidado como trabajo externo a la familia en los cuidadores que tienen derecho a un salario justo por las labores que dicho empleo implica.

Un argumento secundario contra la recompensa económica fue la noción del cuidado como una acción voluntaria. Si se cuida a un familiar por voluntad propia, no es necesaria la recompensa. De acuerdo con Blanca "si es de tu familia, pues no creo que debas recibir nada, simplemente lo haces porque deseas hacerlo y ya". Sin embargo, admiten la legitimidad de recompensar. Casi todos los jóvenes, excepto tres, admitían otros tipos de recompensas: la emocional, la del cuidado futuro y la relación de amistad. En primer término figura la emocional, en tanto que las otras dos son referidas como de menor importancia, ya que pocos las mencionaron y fueron escasamente argumentadas. La satisfacción, la gratitud y el amor o afecto son tres emociones presentes cuando se está implicado en el cuidado. Quien cuida experimenta la satisfacción, ya sea mientras cuida o posteriormente, porque ha ayudado a quien lo necesita, ha realizado una "buena obra" y ha cumplido con su obligación. Así lo expresaba Mariana: "Pues la satisfacción de haber ayudado a alguien que lo necesita, como ellos [los ancianos] que ya están grandes y que no pueden por sí solos, pues yo digo, te queda la satisfacción de haber dicho 'pues yo lo ayudé". Para reforzar la importancia de este aspecto, algunos 
argumentaron en contra: si alguien tuvo la oportunidad de cuidar y no lo hizo, aparece el remordimiento. César fue claro:

si se puede [cuidar] y se decide por no hacerlo, y si tienes condiciones, yo pienso que ahí te queda, como que no te sientes a gusto, si la persona fallece o cualquier cosa, tú te vas a sentir mal porque pudiste ayudar, porque pudiste poner parte de ti, de tu tiempo, de tu dinero. Si no lo haces va a quedar eso y vas a quedar ahí afectado por la situación.

La gratitud es una expresión de reconocimiento a las acciones del otro. Es simplemente dar las gracias, como identificaba Mariana: "el agradecimiento de la persona que le estás ayudando, que te diga 'no, pues gracias', se siente bien". Recibir el amor o el afecto de parte del anciano es de hecho una forma de recompensa. Ésa es la opinión de Mauricio: "es el afecto de la persona" lo que se recibe. Y para Sandra es la recompensa principal: "pues yo creo que lo más importante es el amor de esta persona, y aunque no ganarás nada material, ganas mucho espiritualmente, con el cariño y el aprecio que te dé esta persona”. El segundo tipo de recompensa fue la expectativa de la reciprocidad oblicua, la de recibir cuidado en el futuro cuando envejezca quien cuidó. Este tipo de recompensa alude a la construcción de una cadena de ciclos de reciprocidad que une a los miembros de la misma comunidad (Kittay, 1999: 68), al crear la expectativa de que si el hijo cuidó a sus padres, cuando requiera de ser cuidado en el futuro otros asumirán esa responsabilidad. Los jóvenes no atribuían la obligación a ningún miembro de la familia o a alguien específico. Para Lucía era una posibilidad para sí misma: "O sea, si ayudo a un anciano, ¿por qué lo hago? Porque algún día, llegará el día en que yo no pueda, que yo llegue a ser anciana, que alguien me cuide de la misma manera, sin intereses, nada más". La expectativa está condicionada a cómo se actúe en el presente. César expresaba esto mismo a partir de una amonestación que le habían hecho: a mí se me ha grabado mucho un comentario que me hicieron, de que todo lo que hagas y les dejes de hacer a tus papás, es lo que te van hacer. Había un chavo que trataba mal a su papá y que no sé qué, y ya cuando llegó a anciano terminó tirado ahí en el bote de la basura.

Para fortalecer su argumento los jóvenes citaron el refrán que dice que "en esta vida todo se paga", equivalente a aquel otro de que "se cosecha lo que se sembró". Si el hijo cuidó a sus padres, recibirá cuidado cuando sea viejo, si no lo hizo, tampoco será cuidado. La reciprocidad por cuidado se rige por el principio de dar y recibir el mismo regalo. En este caso, un buen cuidado o la ausencia del mismo. El tercer tipo de recompensa fue la relación de amistad entre el anciano y quien lo cuida. La recompensa es lo que acompaña a la amistad: compartir problemas, pedir consejo, aprender de la vida, conversar. Como decía Alan: "su amistad y sería la persona con la que podrías platicar algún problema o alguna experiencia que él haya tenido, podría ser una muy buena amistad a cambio de nada". Repre la herencia es la forma de corresponderla. Para los ancianos lo ideal es recompensar con la herencia si se poseen bienes, para los jóvenes los recursos no materiales son lo apropiado.

\section{DISCUSIÓN}

Durante varios siglos la herencia de propiedades se afianzó como una práctica para garantizar cuidado a los padres ancianos y recompensar a quien cuidó, pero se fue perdiendo durante el siglo xx. De acuerdo con nuestros hallazgos, también las reglas que norman dicha práctica están cambiando, no así respecto de la obligación filial. En ambas generaciones se identifica una continuidad en las pautas morales para la obligación filial: los hijos tienen la obligación de cuidar a sus padres a cambio del cuidado recibido durante la niñez. Esta continuidad 
tiene implicaciones en las prácticas futuras de cuidado. Los jóvenes entrevistados pertenecen a la generación a la que le corresponderá cuidar a la segunda generación de baby boomers cuando hayan envejecido, entre 2030 y 2040 . Las proyecciones se orientan a un escenario de tensiones debido a los escasos recursos para el cuidado al interior de la familia y a un mayor número de ancianos en México. El índice de dependencia era de 13.7 ancianos por cada 100 jóvenes en 2000 , cifra que aumentará a 57.8 en 2030 y a 92.2 en 2040 . También se considera una escasez de mujeres cuidadoras, quienes tradicionalmente asumen este rol, ya que el índice de disponibilidad de cuidadoras será de 127.2 ancianos por cada 100 mujeres en 2030, de 172.8 en 2040 y de 222.3 en 2050 (Conapo, 2011: 19 y 20), es decir, habrá más personas a quien cuidar y menos cuidadoras potenciales. Frente a este panorama es relevante qué piensan los jóvenes respecto de la obligación filial y de los sistemas de recompensa, ya que ellos serán los sujetos que deberán responder a

La moralidad de la obligación filial de los jóvenes no sólo da continuidad a la establecida por los ancianos, además la refuerza, lo que significa que no sólo es una obligación cuidar a los padres ancianos, sino que no hay justificaciones para mitigar o anular dicha obligación. Esto es importante porque la norma que gobierna el contrato generacional está garantizando el cuidado para la generación futura de ancianos e iría en contra de una visión catastrófica en términos de una "crisis del cuidado" en el futuro inmediato. De acuerdo con nuestros hallazgos, el problema no es la ausencia de obligación, ya que los sujetos poseen una moralidad que los orienta al cumplimiento de la obligación, lo que no se especifica es cuáles serán las formas y las prácticas concretas de cuidado en el futuro. Nuevas evidencias muestran que el cuidado en el hogar y por una mujer de la familia no siempre es la mejor opción para los ancianos, por lo que emergen formas alternativas de cuidado y envejecimiento en comunidad, como las "ciudades de ancianos", el cuidado a distancia, el

cuidado transnacional, los servicios de cuidado a domicilio, entre otros. Opciones cuya finalidad es mantener un cuidado otorgado por la familia, pero en mejores condiciones para los ancianos (Milligan, 2009; Houben, 2000). Frente a una moralidad que refuerza la obligación filial, el debate no sería si estos jóvenes cumplirán, sino cómo cuidarán a sus padres ancianos y cuál será el papel de estas nuevas formas de cuidado en el futuro.

Por otra parte, los hallazgos relativos a la recompensa evidencian una transición entre una y otra generación tendiente a la desaparición de la herencia. Aun cuando los ancianos dan continuidad a la costumbre de heredar al hijo o la hija que los cuidó, los jóvenes rechazan cualquier tipo de recompensa económica y la ubican como una práctica moral inapropiada. Esto supone una transformación que incidirá en las prácticas en torno a la herencia, es decir, a pesar de una norma que obliga la práctica de heredar, ésta se debilita en la actual generación de ancianos. En el futuro dicha práctica tampoco tendrá un sustento normativo que obligue a heredar.

Sin embargo, esta transición no explica cuáles serán las reglas para recompensar en el futuro. El sistema de reglas de los ancianos es claro: una reciprocidad basada en una obligación de compensar por las pérdidas, los sacrificios o los daños sufridos. En este sentido, los ancianos "pagan" con la herencia los sacrificios realizados por el hijo o la hija que los cuidó. Lo relevante no es sólo su carácter de compensación, sino la función de reconocimiento del cuidado como una práctica social con múltiples actividades y responsabilidades, que demanda tiempo y energía, y que mujeres cuidadoras de sectores populares perciben como una responsabilidad "pesada" (Mendez-Luck, Kennedy y Wallace, 2008: 272-274). En cambio, el sistema de los jóvenes es poco claro tanto en sus reglas como en la función de este ciclo y la naturaleza del intercambio. Definen que es aceptable recompensar a quien cuidó, pero no esclarecen las razones para justificar dicha recompensa, lo que deja un vacío 
normativo sobre cuál sería la función de la recompensa. Un asunto central en cualquier ciclo de reciprocidad es definir su función en las interrelaciones sociales. Si bien hay claridad en torno al rechazo de cualquier tipo de recompensa económica, incluida la herencia, no es claro cuál debería ser la naturaleza del bien o el servicio devuelto en sustitución de ésta. Los recursos del capital social señalados como recompensa, en particular los sentimientos y la amistad, están más centrados en la construcción de la relación entre el anciano y quien lo cuida que como una forma de compensación en términos de reciprocidad. Este tipo de intercambio es valorado como gratificante, pero no se define cómo pueden ser utilizados estos recursos fuera de una relación de cuidado ni cuál sería su función en beneficio de quien cuidó, como acontece con la herencia. En este sentido, no es posible identificar cuáles serían las prácticas concretas para recompensar a partir de una normatividad difusa como la de los jóvenes.

Los sistemas de regulación del ciclo dar-recibirdevolver en torno a la obligación filial y la recompensa refieren la voz generacional del grupo social específico de sectores populares. Esto es una limitación de nuestros hallazgos. Un elemento relevante en la comprensión de la moralidad del sentido común es que las condiciones sociales e históricas la estructuran, esto significa que los sistemas de reglas aquí analizados pueden no ser compartidos por otros grupos, como las elites, las clases medias o incluso otros subgrupos de la pobreza. Falta averiguar si es el mismo sistema de reglas y si también está en transición en estos otros grupos sociales, para lo que se requiere más investigación. La otra limitación es que indagamos sobre la obligación filial, la cual media sólo entre padres e hijos, y por tanto no es una obligación universal. La necesidad de trascender esta línea de investigación es un imperativo frente a nuevas formas de envejecimiento, heterogeneidad en las composiciones familiares y circunstancias de vida de los ancianos registradas en las últimas décadas. Esto coloca en el centro del debate nuevas formas de relaciones sociales no sustentadas en el vínculo padre-hijo ni en sus normas. La obligación universal del contrato intergeneracional es que la generación más joven debe proporcionar protección, cuidado y apoyo a la generación de viejos, pero hoy no se finca únicamente en los hijos, sino en otros actores. Es indispensable indagar sobre estos otros ciclos de reciprocidad fuera de la relación filial, pues sólo así sabremos qué está pasando con dichas normas en esta época de transiciones familiares.

\section{BIBLIOGRAFÍA}

Arias, Patricia, 2004, "Las nuevas estrategias de un viejo dilema. ¿Quién hereda la casa en los contextos populares urbanos?", en Journal of Latin American Urban Studies, vol. 6, pp. 19-37.

_ 2005 , "El mundo de los amores imposibles. Residencia y herencia en la sociedad ranchera", en David Robichaux, Familia y parentesco en México y Mesoamérica. Unas miradas antropológicas, Universidad Iberoamericana, México, pp. 547-562.

2009, Del arraigo a la diáspora. Dilemas de la familia rural, Miguel Ángel Porrúa, Guadalajara.

Baier, Kurt, 1966, “II. Moral Obligation", en American Philosophical Quarterly, vol. 3, núm. 3, pp. 210-226.

Beauchamp, Tom, 2003, "A Defense of the Common Morality", en Kennedy Institute of Ethics Journal, vol. 13 , núm. 3, pp. 259-274.

Ben-Amos, Ilana, 2000, "Reciprocal Bonding: Parents and their Offspring in Early Modern England", en Journal of Family History, vol. 25, núm. 3, pp. 291-312.

Bergmann, Jorg, 1998, "Introduction: Morality in Discourse", en Research on Language and Social Interaction, vol. 31, núms. 3 y 4, pp. 279-294.

Consejo Nacional de Población (Conapo), 2011, Diagnóstico socio-demográfico del envejecimiento en México, Consejo Nacional de Población (Serie Documentos Técnicos), México.

Couturier, Edith, 1985, "Women and the Family in Eighteenth-Century Mexico: Law and Practices", en Journal of Family History, vol. 10, núm. 3, pp. 294-304.

Del Rey Poveda, Luis Alberto, 2005, "El nuevo marco de las relaciones intergeneracionales en las familias ejidales: migración y herencia en el sur de Veracruz", en Estudios Agrarios, vol. 28, pp. 151-193. 
Fairclough, Norman, 2003, Analysing Discourse. Textual Analysis for Social Research, Routledge, Londres.

Green, David y Alastair Owens, 2004, "Introduction: Family Welfare and the Welfare Family", en David Green y Alastair Owens, Family Welfare. Gender, Property, and Inheritance since the Seventeenth Century, Praeger, Westport, pp. 1-30.

Hareven, Tamara, 1994, "Aging and Generational Relations: A Historical and Life Course Perspectives", en Annual Review of Sociology, vol. 20, pp. 437-461.

Houben, Piet, 2000, "Towards a Conceptual Framework for 'Ageing in Place' of Frail Older Adults”, en European Journal of Social Quality, vol. 2, núm. 1, pp. 47-65.

Kellogg, Susan, 1986, "Aztec Inheritance in SixteenthCentury Mexico City: Colonial Patterns, Prehispanic Influences", en Ethnohistory, vol. 33, núm. 3, pp. 315330.

Kertzer, David y Caroline Brettell, 1987, "Advances in Italian and Iberian Family History", en Journal of Family History, vol. 12, núms. 1-3, pp. 87-120.

Kittay, Eva Feder, 1999, Love's Labor. Essays on Women, Equality, and Dependency, Routledge, Nueva York.

Kuhn, Deanna, 1991, The Skills of Argument, Cambridge University Press, Cambridge.

Lamar, Marti, 1994, "Choosing Partible Inheritance: Chilean Merchant Families, 1795-1825”, en Journal of Social History, vol. 28, núm. 1, pp. 125-145.

Levine, Sarah, 1986, "Widowhood in Los Robles: ParentChild Relations and Economic Survival in Old Age in Urban Mexico", en Journal of Cross-Cultural Geronto$\log y$, vol. 1, núm. 3, pp. 223-237.

Mannheim, Karl, 1963, “The Problem of Generations”, en Psychoanalytic Review, vol. 57, núm. 3, pp. 378-404.

Mauss, Marcel, 2009, Ensayo sobre el don. Forma y función del intercambio en las sociedades arcaicas, Katz, Buenos Aires.

McLeod, Julie y Rachel Thomson, 2009, Researching Social Change. Qualitative Approaches, SAGE, Los Ángeles.

Mendez-Luck, Carolyn, David Kennedy y Steven Wallace, 2008, "Concepts of Burden in Giving Care to Older Relatives: A Study of Female Caregivers in a Mexico
City Neighborhood", en Journal of Cross Cultural Gerontology, vol. 23, núm. 3, pp. 265-282.

Milligan, Christine, 2009, There's no Place Like Home: Place and Care in an Ageing Society, Ashgate Publishing Limited, Farhman.

Oxhorn, Philip, 1998, “The Social Foundations of Latin America's Recurrent Populism: Problems of Popular Sector Class Formation and Collective Action", en Journal of Historical Sociology, vol.11, núm. 2, pp. 212-246.

Poska, Allyson, 2000, "Gender, Property, and Retirement Strategies in Early Modern Northwestern Spain”, en Journal of Family History, vol. 25, núm. 3, pp. 313-325.

Robichaux, David, 1997, "Residence Rules and Ultimogeniture in Tlaxcala and Mesoamerica", en Ethnology, vol. 32, núm. 2, pp. 149-171.

, 2007, "Sistemas familiares en culturas subalternas de América Latina: una propuesta conceptual y un bosquejo preliminar", en David Robichaux, Familia y diversidad en América Latina. Estudios de casos, Consejo Latinoamericano de Ciencias Sociales, Buenos Aires, pp. 27-75.

Robles, Leticia, 2007, "La designación de cuidadoras de padres enfermos: la ultimagenitura femenina en un sector popular urbano de Guadalajara", en David Robichaux, Familias mexicanas en transición. Unas miradas antropológicas, Universidad Iberoamericana, México, pp. 353-370.

Sánchez-Peña, Landy, 2012, "Alcances y límites de los métodos de análisis espacial para el estudio de la pobreza urbana”, en Papeles de Población, vol. 18, núm. 72, pp. 147-180.

Varley, Ann y Maribel Blasco, 2000, "Intact or in Tatters? Family Care of Older Women and Men in Urban Mexico", en Gender and Development, vol. 8, núm. 2, pp. 47-55.

Vázquez, Daniel, 1992, "La urbanización de Guadalajara", en Lina Rendón, Capítulos de la historia de Guadalajara, Ayuntamiento de Guadalajara, Guadalajara, pp. 39-70.

Ward, Peter et al., 2011, "Self-Help Housing for Second Generation Inheritance and Succession of 'The House that Mum \& Dad Built"', en Habitat International, vol. 35, pp. 467-485. 